\title{
Early and late results of partial plication annuloplasty for congenital mitral insufficiency
}

Takaaki Sugita, MDa

Yuichi Ueda, MD

Masahiko Matsumoto, MDa

Hitoshi Ogino, MDa

Jun-ichiro Nishizawa, MDa

Katsuhiko Matsuyama, MDa
From the Department of Cardiovascular Surgery, Tenri Hospital, Nara, ${ }^{\mathrm{a}}$ and the Department of Cardiovascular Surgery, Nagoya University, Nagoya, ${ }^{\mathrm{b}}$ Japan.

Received for publication July 12, 2000; revisions requested Sept 27, 2000; revisions received Oct 23, 2000; accepted for publication Feb 14, 2001

Address for reprints: Takaaki Sugita, MD, Department of Cardiovascular Surgery, Tenri Hospital, 200 Mishima, Tenri, Nara, 6328552 Japan.

J Thorac Cardiovasc Surg 2001;122:229-33

Copyright (c) 2001 by The American Association for Thoracic Surgery

$0022-5223 / 2001 \$ 35.00+0 \quad \mathbf{1 2 / 1 / 1 1 5 1 5 7}$

doi:10.1067/mtc.2001.115157
Background: Partial plication annuloplasty is the main technique for congenital mitral insufficiency because this technique allows the mitral anulus to grow, in contrast to ring annuloplasty. However, this technique is not satisfactory for mitral insufficiency with some anomalies of the mitral valve apparatus.

Methods: Forty-one patients underwent partial plication annuloplasty for mitral regurgitation from July 1979 to December 1998. Mitral regurgitation associated with an atrioventricular defect, an atrioventricular discordance, and a univentricular heart was excluded from this study.

Results: There were no early or late deaths. In early results, partial plication annuloplasty was more effective for mitral regurgitation with abnormality of the posterior leaflet $(n=14)$ or normal leaflet motion $(n=8)$ than with abnormality of the anterior leaflet and its apparatus $(n=14)$ or absence of chordae $(n=4)$. The mean follow-up period was 145.8 months. During the follow-up period, 2 patients underwent mitral valve replacement, and a third patient underwent mitral valve repair with partial plication annuloplasty after the first repair. The main cause of mitral regurgitation of 2 of the 3 patients was absence of chordae. The actuarial freedom from reoperation rate was $94.9 \% \pm 3.6 \%, 91.9 \% \pm 4.7 \%$, and $91.9 \% \pm 4.7 \%$ at 5 , 10 , and 15 years after the operation, respectively.

Conclusion: Early and long-term results of partial plication annuloplasty were acceptable for congenital mitral insufficiency with any type of malformation of the mitral valve, and results were excellent with abnormality of the posterior leaflet and its apparatus or normal leaflet motion. However, late results were suboptimal for mitral regurgitation with absence of chordae. Other techniques, such as artificial chorda replacement, should be adapted in these cases.

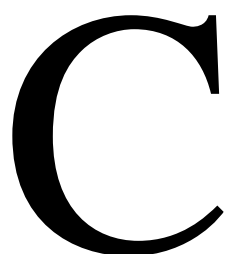

ongenital mitral regurgitation (MR) is rare. However, because it is clinically important, reports of numerous techniques and their results have been published. ${ }^{1-10}$ We mainly have been using partial plication annuloplasty for MR in children because this technique allows the mitral anulus to grow, in contrast to ring annuloplasty, and the technique is simple and easy. There have been very few reports concerning the early and long-term results of partial annular plication. ${ }^{1-4}$ We did a retrospective analysis of our clinical experience with this treatment. 

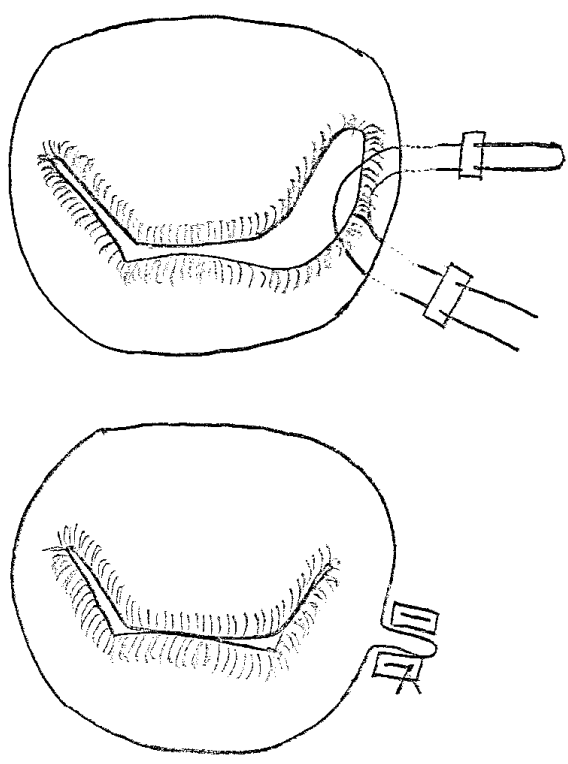

Figure 1. The partial plication annuloplasty comprises exclusion of the lateral or medial scallop of the posterior leaflet at the corresponding commissure by using a few buttressed mattress sutures.

\section{Patients and Methods}

Between July 1979 and December 1998, 46 consecutive patients less than 16 years of age underwent mitral valve repair for MR in Tenri Hospital. Forty-one patients underwent partial plication annuloplasty, ${ }^{11,12} 2$ underwent rigid ring annuloplasty, ${ }^{13,14} 2$ underwent De Vega-like annuloplasty, ${ }^{15}$ and 1 underwent plication of the anterior leaflet only. ${ }^{1}$

In 41 patients with partial plication annuloplasty, 14 concomitant procedures were performed (plication of anterior leaflets, 6; suture of the cleft, 5; plication of the posterior leaflets, 2; and implantation of artificial chordae, 1).

Ascending aortic and bicaval cannulation was used for all operations, and moderate hypothermic cardiopulmonary bypass was maintained. Cardiac arrest was obtained with the use of blood or crystalloid cardioplegic solution. The operative methods mainly consisted of asymmetric annuloplasty after the Kay-Reed method. ${ }^{11,12}$ This comprises exclusion of the lateral or medial scallop of the posterior leaflet at the corresponding commissure by means of a few buttressed mattress sutures (Figure 1). ${ }^{1}$

Four patients were infants. Eighteen were boys, and 23 were girls. There were no associated anomalies in 14 patients, ventricular septal defects in 14 patients, atrial septal defects in 8 patients, patent ductus arteriosus in 3 patients, aortic valve stenosis in 1 patient, and anomalous connection of the left coronary artery to the pulmonary artery in 1 patient. The preoperative degree of MR followed by the criteria of Sellers and associates ${ }^{16}$ was $2+$ in $6,3+$ in 24 , and $4+$ in 11 patients. The main causes of MR were abnormality of the anterior leaflet and its apparatus (anterior leaflet group, $\mathrm{n}$ $=15$ ), abnormality of the posterior leaflet and its apparatus (posterior leaflet group, $n=14$ ), absence of unilateral chordae (chordae group, $n=4$ ), and mitral valve incompetence with normal leaflet motion (other group, $\mathrm{n}=8$; same as type III of Carpentier's classi- fication $^{5}$ ). Mean preoperative degrees of MR were $3.3 \pm 0.6$ in the anterior leaflet group, $2.9 \pm 0.6$ in the posterior leaflet group, $3.4 \pm$ 0.5 in the other group, and $2.5 \pm 0.6$ in the chordae group. Mean preoperative degrees of MR of the anterior leaflet and other groups were significantly higher than those in the chordae group $(P<.05)$.

The follow-up period was from 2 to 246 months (mean, 145.8 months; median, 180.0 months). In the follow-up period the echocardiographic evaluation was performed mainly for the patients who had general fatigue, dyspnea on exertion, and palpitation. Reoperation was scheduled if a disgnosis of cardiac failure caused by MR was made. Cumulative freedom from reoperation was calculated with the Kaplan-Meier method. Data were compared among 4 groups by analysis of variance. All data are expressed as means $\pm \mathrm{SD}$.

\section{Results \\ Early Results}

There were no early deaths in this group. Eight patents underwent postoperative left ventriculography, 26 patients underwent postoperative echocardiography, and 7 patients underwent no assessment. Echocardiographic grades were based on the length of the regurgitation jet relative to left atrial size and classified from 0 to $3 .{ }^{17}$ For comparison of the degree of MR between echocardiography and left ventriculography, Seller's classification was also classified from 0 to 3: Seller's classification of 1 or 2 was defined as echocardiographic grade 1; Seller's classification 3 was defined as echocardiographic grade 2; and Seller's classification 4 was defined as echocardiographic grade 3. ${ }^{1}$ Postoperative degree of MR by means of echocardiography was $0+$ in 7 patients, $1+$ in 14 patients, $2+$ in 12 patients, and $3+$ in 1 patient. The patients whose postoperative degree of MR was 3+ underwent mitral valve replacement 3 months after the operation. Mean postoperative degree of MR was $1.5 \pm 0.8$ in the anterior leaflet group $(\mathrm{n}=13), 0.9 \pm 0.8$ in the posterior leaflet group $(n=11), 0.9 \pm 0.7$ in the other group $(n=6)$, and $2.0 \pm 0$ in the chordae group $(n=4)$. Mean postoperative degree of MR of the anterior leaflet group was significantly higher than that of the posterior leaflet and other groups $(P<.05)$, and mean postoperative degree of MR of the chordae group was significantly higher than that of the posterior leaflet and other groups (Figure 2).

\section{Late Results}

There were no late deaths and no embolic episodes in this group. Two patients underwent mitral valve replacement 3 and 51 months after their operations, and 1 patient underwent a second mitral valve repair with partial plication annuloplasty. The actuarial freedom from reoperation rate was $94.9 \% \pm 3.6 \%, 91.9 \% \pm 4.7 \%$, and $91.9 \% \pm 4.7 \%$ at 5 , 10 , and 15 years after the operation, respectively (Figure 3 ).

In the patients who underwent reoperation, the cause of MR of the 2 patients was absence of chordae (group C). As 


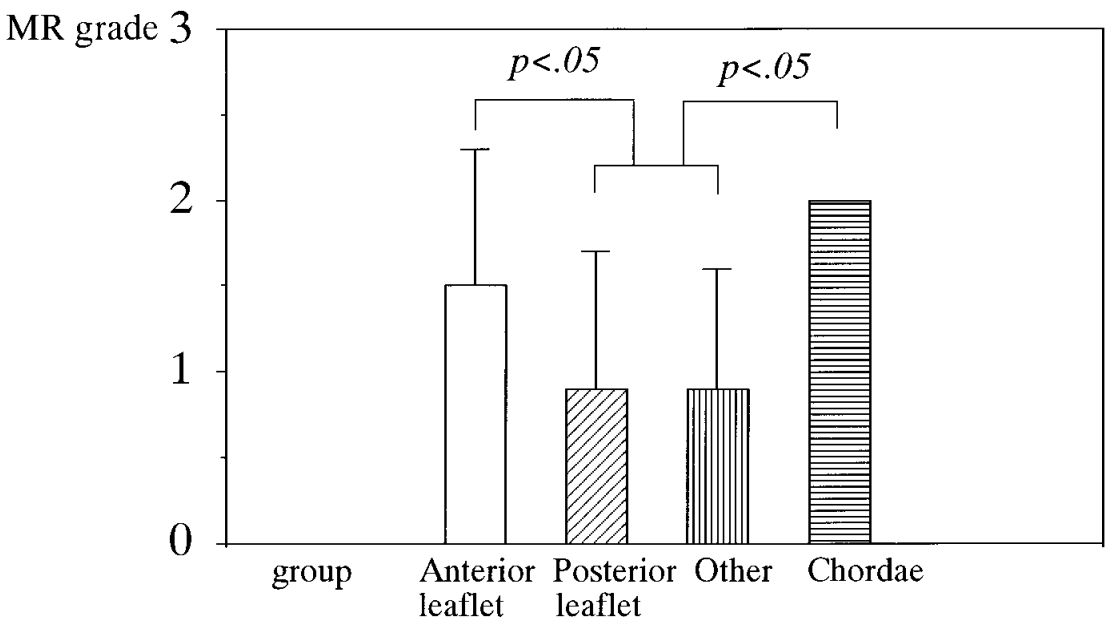

Figure 2. Mean postoperative degree of MR of the anterior leaflet, posterior leaflet, other, and chordae groups.

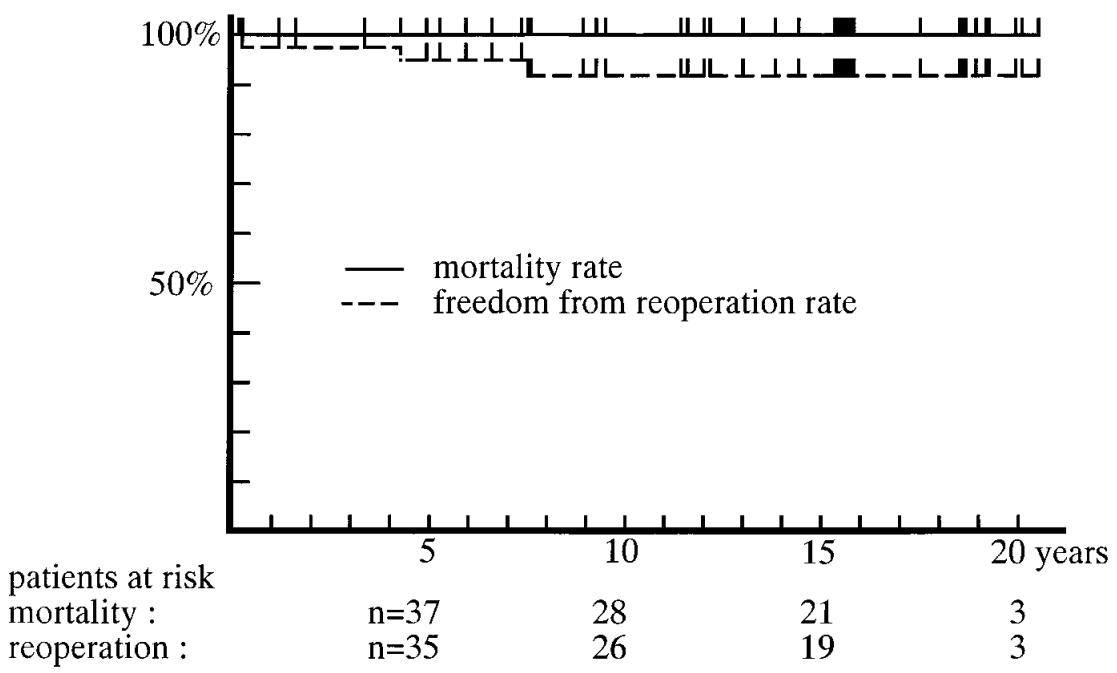

Figure 3. Actuarial survival curve and freedom from reoperation curve.

a result, of the 4 patients of the chordae group, 2 (50\%) underwent reoperation. Also, 1 patient from the anterior leaflet group underwent reoperation. Including these 3 patients who underwent reoperation, 6 patients were determined to have more than 3 degrees of MR by means of echocardiography during the follow-up period. The remaining 3 patients who had 3 degrees of MR were only monitored because there were few signs of volume overload to the left ventricle, and no patient had symptoms of heart failure. The cause of MR in the 3 patients was absence of chordae (chordae group, $75 \%$ ), and 3 patients had abnormality of the anterior leaflet and its apparatus (anterior leaflet group, 20\%; 1 patient underwent reoperation).

\section{Discussion}

MR in childhood may be caused by anomalies of a component of the mitral apparatus, such as chorda, leaflet, papillary muscle, annular dilatation, or their combination. Moreover, such anomalies were frequently associated with other congenital lesions. For these reasons, mitral valve repairs were suboptimal in some cases. Recently, Ibrahim and colleagues ${ }^{18}$ reported good early and long-term results of mitral valve replacement with prosthetic valves; however, many reports commented that prosthetic valve replacements are associated with significant morbidity and mortality and suboptimal long-term results. ${ }^{8,19,20}$ Moreover, lasting anticoagulation therapy and reoperation after small- 
valve implantation were inevitable, and precise control of warfarin dosage is troublesome, especially in small children. Therefore, mitral valve repair is desired for MR in children.

Mitral repairs for MR in adults were performed with many techniques, such as quadrant resection of the leaflet, chordal transfer or replacement, artificial chordae, partial annuloplasty, and ring annuloplasty, ${ }^{13,14}$ and we are aware of the low operative mortality and minimal postoperative complications in cases in which these procedures are used to treat adult patients. Treatment of the fragile mitral valve apparatus, especially in small children, might be difficult and risky, and long-term results of artificial chordae were not known previously; we did not use these techniques. Ring annuloplasty with a rigid or flexible ring for MR was accepted with optimal early and long-term results. ${ }^{13,14}$ However, in children ring annuloplasty might disturb the growth of the mitral valve anulus, and reoperation might be inevitable. Therefore, we used a rigid ring for mitral annuloplasty for the patients more than 10 years of age (2 patients); however, many patients were less than 10 years of age, and we mainly used partial plication annuloplasty for MR in these children.

Early and late results of partial plication annuloplasty were excellent in our series. There were only 3 reoperations after mitral valve repair. The need for reoperation generally occurs within 2 years of the initial valve repair. ${ }^{21}$ However, we performed reoperation 51 and 90 months after the operation. In these patients MR after the operation was grade 2, and their condition deteriorated during the follow-up period. Therefore, we should perform careful follow-up for the remaining 3 patients who had 3 degrees of MR.

In early and late results, the type of anomalies of mitral valve was an important factor. Carpentier classified the mitral valve malformations in 3 types: type I, mitral valve incompetence with normal leaflet motion; type II, leaflet prolapse; and type III, restricted leaflet motion. However, we classified the cause of MR into 4 types in this report: (1) abnormality of the anterior leaflet and its apparatus; (2) abnormality of the posterior leaflet and its apparatus; (3) absence of unilateral chordae; and (4) mitral valve incompetence with normal leaflet motion (same as type III of Carpentier's classification). Because partial annuloplasty comprises exclusion of the lateral and/or medial scallop of the posterior leaflet, better results were expected for the patients whose posterior leaflet was prolapsed or restricted than for the patients whose anterior leaflet was prolapsed. In other words, the success of this procedure depends to a great extent on which leaflet (anterior and posterior) is prolapsed or restricted. In fact, we could repair prolapse or restriction of the posterior leaflet easily with this partial plication annuloplasty. However, the early results of the repair of MR with abnormality of the anterior leaflet and its apparatus and absence of unilateral chordae were not as good as MR with these anomalies. We could repair the prolapse of the anterior leaflet with plication of the anterior leaflet, but we could not repair the restriction of anterior leaflet and absence of unilateral chordae. Ohno and colleagues ${ }^{3}$ also commented that patients with chordal anomalies, except for elongation, more often required valve replacement.

Late results of MR with abnormality of the anterior leaflet and its apparatus were acceptable; however, late results of MR for absence of unilateral chordae were suboptimal. Recently, good early and midterm results of artificial chordae for mitral valve reconstruction in children have been reported. ${ }^{9,10}$ We believe we can manage MR with absence of unilateral chordae by using this technique and will adapt this technique for MR with absence of unilateral chordae, considering the poor results of partial plication annuloplasty for MR with absence of unilateral chordae.

Early and long-term results of partial plication annuloplasty were acceptable for MR with any type of malformation of the mitral valve, and results were excellent with abnormality of the posterior leaflet and its apparatus or normal leaflet motion. However, late results were suboptimal for MR with absence of chordae. Other techniques, such as artificial chordal replacement, should be adapted in these cases.

\section{References}

1. Okita Y, Miki S, Kusuhara K, et al. Early and late results of reconstructive operation for congenital mitral regurgitation in pediatric age group. J Thorac Cardiovasc Surg. 1988;96:294-8.

2. Hisatomi K, Isomura T, Sato T, Kosuga K, Ohishi K, Katoh H. Mitral valve repair for mitral regurgitation with ventricular septal defect in children. Ann Thorac Surg. 1996;62:1773-7.

3. Ohno H, Imai Y, Terada M, Hiramatsu T. The long-term results of commissure plication annuloplasty for congenital mitral insufficiency. Ann Thorac Surg. 1999;68:537-41.

4. Uva MS, Galletti L, Gayet FL, et al. Surgery for congenital mitral valve disease in the first year of life. J Thorac Cardiovasc Surg. 1995;109:164-76.

5. Chauvaud S, Fuzellier JF, Houel R, Berrebi A, Mihaileanu S, Carpentier A. Reconstructive surgery in congenital mitral valve insufficiency (Carpentier's techniques): long-term results. J Thorac Cardiovasc Surg. 1998;115:84-93.

6. McCarthy JF, Neligan MC, Wood AE. Ten year's experience of an aggressive reparative approach to congenital mitral valve anomalies. Eur J Cardiothorac Surg. 1996;10:534-9.

7. Zias EA, Mavroudis C, Backer CL, Kohr LM, Gotteiner NL, Rocchni AP. Surgical repair of the congenitally malformed mitral valve in infants and children. J Thorac Cardiovasc Surg. 1998;66:1551-9.

8. Yoshimura N, Yamaguchi M, Oshima Y, et al. Surgery for mitral valve disease in the pediatric age group. J Thorac Cardiovasc Surg. 1999;118:99-106.

9. Murakami T, Yagihara T, Yamamoto F, Uemura H, Yamashita K, Ishizaka T. Artificial chordae for mitral valve reconstruction in children. Ann Thorac Surg. 1998;65:1377-80.

10. Matsumoto T, Kado H, Matsuda M, et al. Clinical results of mitral valve repair by reconstructing artificial chordae tendineae in children. J Thorac Cardiovasc Surg. 1999;118:94-8.

11. Kay JH, Egerton WS, Zubiate P. The surgical treatment of mitral insufficiency and combined mitral stenosis and insufficiency using the heart-lung machine. Surgery. 1961;50:67-75. 
12. Reed GE, Tice DA, Clauss RH. Asymmetric exaggerated mitral annuloplasty: repair of mitral insufficiency with hemodynamic predictability. J Thorac Cardiovasc Surg. 1965;49:752-61.

13. Kirklin JW, Barratt-Boyes B. Mitral valve disease with or without tricuspid valve disease. In: Kirklin JW, Barratt-Boyes B, editors. Cardiac surgery. 2nd ed. New York: Churchill Livingstone; 1993. p. 425-91.

14. Muehrcke DD, Cosgrove DM. Mitral valve plasty. In: Edmunds Jr LH, editor. Cardiac surgery in the adult. New York: McGraw-Hill; 1997. p. 991-1024.

15. De Vega NG. La anuloplastia selectiva, regulable y permanente. Una tecnica original para el tratamiento de la insuficiencia tricuspide. Rev Esp Cardiol. 1972;25:555-6.

16. Sellers RD, Levy MJ, Amplatz K, Lillehei CW. Left retrograde cardioangiography in acquired cardiac disease: technic, indications and inter presentation in 700 cases. Am J Cardiol. 1964;14:437-47.
17. Miyatake K, Izumi S, Okamoto M, et al. Semiquantitive grading of severity of mitral regurgitation by real-time two-dimensional Doppler flow imaging technique. J Am Coll Cardiol. 1986;7:82-8.

18. Ibrahim M, Cleland J, O'Kane H, Gladstone D, Mullholland C, Craig B. St. Jude medical prosthesis in children. J Thorac Cardiovasc Surg. 1994;108:52-6.

19. Fiane AE, Lindberg HL, Saatvedt K, Svennevig JL. Mechanical valve replacement in congenital heart disease. J Heart Valve Dis. 1996;5:337-72.

20. Duran CMG, Gometza B, Martin-Duran R, Saad E, Al-Halees Z. Performance of 96 Carbomedics valve replacements in 75 patients less than twenty-one years of age. Ann Thorac Surg. 1994;58:639-45.

21. Chauvaud S, Perier P, Touati G, et al. Long-term results of valve repair in children with acquired mitral valve incompetence. Circulation. 1986;74(Suppl):I-104-9.

\section{Notice of correction}

In the February 2001 issue of the Journal, in the article by Stooker and associates titled "Perivenous Support Reduces Early Changes in Human Vein Grafts: Studies in Whole Blood Perfused Human Vein Segments" (2001;121:290-7), the authors would like to cite the specific grant received by Dr Niessen. In the footnotes on page 290, the grant citation should read: "Dr Niessen is a recipient of the Dr Dekker program of the Netherlands Heart Foundation (D99025)." The correct citation is available online at www.mosby.com/jtcvs. 